\title{
STRATEGI PENINGKATAN \\ MUTU CALON GURU PAI \\ MELALUI PENGEMBANGAN SOFT SKILL \\ DI PERGURUAN TINGGI AGAMA ISLAM
}

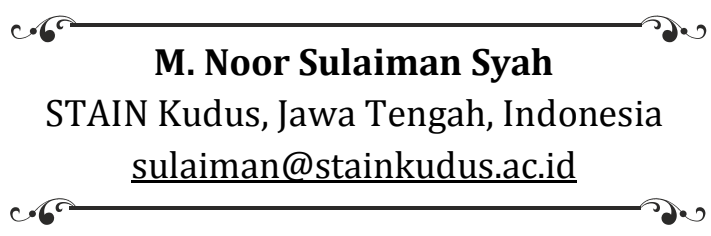

\begin{abstract}
STRATEGY OF INCREASING THE ISLAMIC TEACHERS CANDIDATE QUALITY THROUGH SOFT SKILL DEVELOPMENT IN ISLAMIC COLLEGE. The purpose of this research is to know the strategy of improving the quality of Islamic Religious Education teacher candidate in STAIN Kudus. The research method used is qualitative research method. This research used observation, interview and $d$ ocumentation for the data collection tools and analyzed by using interactive analysis. The result of the research shows that the strategy of improving the quality of Islamic Religious Education teachers in STAIN is divided into several strengthenings, namely strengthening of Islam, strengthening the field of PAI study, as well as the strengthening of foreign languages (English and Arabic), both through intra-curricular or co-curricular. Changes in the world of work in educational institutions should be prepared by universities preparing educators and other education personnel so that a student must be trained and trained to have the competencies described in three levels; perform, manage, and evaluate the process.
\end{abstract}

Keywords: Quality Improvement, Prospective Teachers, Soft Skill Development.

Abstrak: Tujuan Penelitian ini adalah mengetahui Strategi Peningkatan mutu calon Guru Pendidikan Agama Islam di STAIN Kudus. Metode Penelitian yang dipakai adalah metode penelitian kualitiatif. Alat pengumpul data memakai observasi, wawancara dan dokumentasi. Analisis data menggunakan analisis interaktif. Hasil penelitian menunjukkan bahwa strategi Peningkatan mutu 


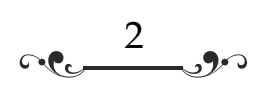

calon Guru Pendidikan Agama Islam di STAIN dibagi menjadi beberapa penguatan, yakni penguatan ke-Islam-an, penguatan bidang studi PAI, maupun penguatan bahasa asing (Bahasa Inggris dan Bahasa Arab), baik yang diberikan melalui kegiatan intrakurikuler maupun ko-kurikuler. Perubahan dunia kerja di lembaga pendidikan harus disiapkan oleh Perguruan Tinggi yang mempersiapkan tenaga pendidik dan tenaga kependidikan lainnya sehingga seorang mahasiswa harus dididik dan dilatih untuk memiliki kompetensi yang terjabarkan dalam tiga tingkatan; melakukan, mengelola, dan mengevaluasi serta memodifikasi proses.

Kata Kunci: Peningkatan Mutu, Calon Guru, Pengembangan Soft Skill.

\section{A. Pendahuluan}

Globalisasi dan arus informasi yang pesat berimbas pada pembangunan di seluruh dunia. Untuk dapat terus mengikuti perubahan dan tantangan zaman, manusia senantiasa berupaya meningkatkan potensi dirinya agar menjadi manusia yang berdaya kualitas tinggi. Kualitas sumber daya manusia dipengaruhi oleh perubahan sosial yang sangat cepat dan dramatis yang mensyaratkan perubahan pada sistem pendidikan. Pendidikan yang semula hanya cukup memberikan dasar kompetensi akademik pada lulusannya, saat ini perlu untuk memikirkan juga bagaimana melengkapi kompetensi tersebut dengan kompetensi lain yang dapat digunakan untuk menghadapi tantangan perubahan sosial yang ada. Keadaan ini tidak hanya dialami oleh pendidikan di Indonesia, akan tetapi juga dialami oleh sebagian besar pendidikan baik di Eropa, Amerika maupun Asia dan Afrika.

Perkembangan dunia pendidikan di Indonesia khususnya pada tingkat perguruan tinggi telah mengalami pergeseran ke arah pembentukan kompetensi lulusan. Kompetensi lulusan menjadi salah satu faktor penanda keberhasilan sebuah perguruan tinggi dalam menjalankan visi dan misinya. Senada dengan amanat dalam strategi kebijakan Kementerian Pendidikan Nasional, yaitu "Mewujudkan Insan Indonesia yang Cerdas dan Kompetitif Tahun 2025", 


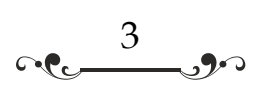

maka peningkatan daya saing lulusan sebagai salah satu output dari pendidikan tinggi telah menjadi prioritas utama di setiap program perguruan tinggi. Upaya peningkatan kualitas lulusan ini, selain dilakukan melalui sistem pembelajaran yang komprehensif, efektif dan transformatif, juga dikembangkan melalui program pembinaan kemahasiswaan yang diarahkan agar memiliki pengetahuan (kognitif), sikap (afektif) dan keterampilan (psikomotorik) sehingga memberikan nilai tambah (added values) guna meningkatkan daya saing lulusan.

Pendidikan di perguruan tinggi dihadapkan pada situasi untuk selalu bergerak dalam mengedepankan output-nya yaitu lulusan yang berkualitas (memiliki kompetensi). Istilah kualitas merupakan kata kunci yang sangat penting dalam penyelenggaraan pendidikan tinggi.

Kompete

D.onsi lulusan (sarjana) tidak hanya pada bidang keilmuannya saja, akan tetapi juga pada kompetensi-kompetensi penunjang yang akan meningkatkan daya tawar (bargaining power) para lulusan (sarjana) pada saat memasuki pasar tenaga kerja.

Kompetensi yang dimaksudkan dalam Keputusan Menteri Pendidikan Nasional Republik Indonesia Nomor 232/U/2000, tentang Pedoman Penyusunan Kurikulum Pendidikan Tinggi dan Penilaian Hasil Belajar Mahasiswa, menunjukkan bahwa selain kompetensi pada bidang ilmunya juga dituntut adanya kompetensikompetensi tambahan. Hal ini tentu saja membawa konsekuensi bagi lembaga pendidikan terutama perguruan tinggi untuk menghasilkan lulusan yang berkompetensi (berkualitas) dalam arti yang luas dan mampu memenuhi permintaan pasar kerja, dimana penguasaan berbagai teknologi baru dan keterampilan termasuk soft skill semakin dituntut. Apabila dicermati, maka rasio kebutuhan soft skill dan hard skill di dunia kerja menunjukkan bahwa yang membawa orang di dalam sebuah kesuksesan, 80\% ditentukan oleh soft skill yang dimilikinya dan $20 \%$ oleh hard skill. Namun sistem pendidikan di Indonesia saat ini, soft skill hanya diberikan rata-rata $10 \%$ saja dalam kurikulum (Illah, 2007: 9).

Menelitik fenomena di atas, hal serupa juga terjadi dalam lulusan mahasiswa Pendidikan Agama Islam sebagai calon guru 


\section{r.e. 4.0}

Pendidikan Agama Islam. Dilihat dari aspek guru sesuai standar nasional, guru Pendidikan Agama Islam masih belum memenuhi standar kualifikasi terutama ketentuan PP No. 19 Tahun 2006 tentang Standar Nasional Pendidikan pasal 29 yang menyatakan bahwa setiap pendidik di semua jenjang minimal harus lulus strata 1 atau diploma IV (S-1/D-IV). Secara riil kondisi ini belum terpenuhi. Departemen Agama membuat salah satu kebijakan strategis di bidang peningkatan mutu, relevansi dan daya saing dengan cara rekrutmen pendidik dan tenaga kependidikan berdasarkan kualifikasi dan kompetensi. Namun, perekrutan pendidik dari lulusan strata 1-pun tidak secara otomatis mendogkrak mutu pembelajaran PAI. Meskipun guru sudah didik di tingkat sarjana tidak secara otomatis mereka memiliki kompentensi sesuai peraturan yang berlaku. Apalagi calon guru PAI yang terdapat hampir di semua Perguruan Tinggi Agama Islam (PTAI) baik swasta maupun negeri memiliki mahasiswa yang paling banyak dibandingkan dengan jurusan yang lainnya. Perguruan Tinggi Agama Islam (PTAI) di bawah Departemen Agama (Depag) RI yang sampai sekarang mencapai jumlah 577 buah (53 Negeri dan 524 Swasta) sebagian besar atau sekitar $90 \%$ menyelenggarakan jurusan/Program Studi PAI. Keadaan semacam ini menjadikan kontrol kualitas terabaikan.

Kualitas calon guru PAI yang belum memenuhi standar ini menunjukkan bahwa apa yang diberikan di bangku kuliah kurang lagi sesuai dengan apa yang dibutuhkan di lapangan. Sebagian besar menu yang disajikan di perguruan tinggi adalah berupa hard skill atau keterampilan keras. Sementara itu banyak bukti menunjukkan bahwa penentu keberhasilan seseorang di luar bangku kuliah sangat dipengaruhi oleh keahlian yang tergolong keahlian lunak atau soft skill. Ketidak seimbangan ini tentu saja perlu segera diatasi antara lain dengan memberikan bobot yang lebih pada pengembangan soft skill untuk mahasiswa di perguruan tinggi. Hal ini juga didukung oleh laporan Professional Standarts Council New South Wales yang dikutip Asia Pacific of Journal Cooperative Education (2005) yang menyebutkan: "It challenges to recognize the importance of soft skill to professional competence and to develop programs to increase proficiency in these areas" (Tantangan ini mengakui pentingnya soft 


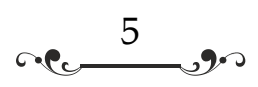

skill untuk kompetensi profesional dan mengembangkan program peningkatan kemampuan di bidang tersebut).

Sehubungan dengan hal tersebut, maka penulis akan memaparkan strategi peningkatan mutu calon guru PAI melalui pengembangan soft skill yang dihasilkan dari penelitian kualitiatif pada mahasiswa jurusan PAI semester akhir di STAIN Kudus. Alat pengumpul data yang digunakan adalah observasi, interview dan dokumentasi, sedangkan analisis data dengan menggunakan analisis interaktif.

\section{B. Pembahasan}

\section{Strategi Peningkatan Mutu Pendidikan}

Mutu pendidikan dijelaskan pada pasal 1 ayat 17 UU RI Nomor 20 Tahun 2003; yakni: "Standar nasional pendidikan adalah kriteria minimal tentang sistem pendidikan di seluruh wilayah hukum Negara Kesatuan Republik Indinesia". Sedangkan kriteria minimal standar nasional pendidikan terdiri atas standar isi, proses, kompetensi lulusan, tenaga kependidikan, sarana dan prasarana, pengelolaan, pembiayaan, dan penilaian pendidikan yang harus ditingkatkan secara berencana (Pasal 35 ayat 1 UU RI Nomor 20 Tahun 2003).

Untuk mencapai standar mutu dari pendidikan itu bukan hanya unsur tenaga kependidikan atau dosen, standar isi, proses, sarana dan prasarana, pengelolaan, pembiayaan, dan penilaian pendidikan tetapi juga kompetensi lulusan di perguruan tinggi; yang dapat dilaksanaakan oleh suatu badan standarisasi, penjaminan dan pengendalian mutu pendidikan (Pasal 35 ayat 3 UU RI Nomor 20 Tahun 2003).

Sedangkan strategi mutu pendidikan berarti bagaimana mutu pendidikan tersebut harus dirubah dengan strategi yang tepat. Strategi perubahan ditujukan agar organisasi menjadi lebih efektif dalam mencapai tujuannya. Dalam rangka inilah diperlukan usaha untuk merubah organisasi dengan memperhatikan berbagai faktor yang terkait. Indrawijaya (1989: 28) mengemukakan bahwa: "Usaha para manajer untuk memperbaiki atau merubah organisasi pada masa yang lampau lebih banyak dipusatkan pada perubahan: (1) 


\section{r.e. 6}

subsistem teknologi; (2) subsistem manajerial; atau (3) subsistem manusia".

Melakukan perubahan itu memang tidak mudah, karena itu perlu disusun perencanaan yang matang, sehingga dihasilkan rencana, program dan kebijakan yang tepat untuk selanjutnya dilakukan penerapan secara konsisten. Unsur yang dapat dirubah itu tidak selalu seluruhnya dilakukan perubahan; salah satu saja dapat dilakukan berarti telah melakukan perubahan; sebagaimana dijelaskan oleh Robbins (dalam Udaya, 1994: 428) bahwa: strategi cenderung masuk salah satu kategori dari empat kategori yang ada: manusia, struktur, teknologi, dan proses organisasi. Bahwa jika ada kekuatan yang memprakarsai perubahan, ada seseorang yang menerima peran sebagai agen perubahan, dan telah ditetapkan apa yang harus dibuang, maka kita perlu memperhatikan bagaimana melaksanakan perubahan tersebut. Kita mulai melihat dengan langkah-langkah dalam proses perubahan tersebut.

Keberhasilan perubahan membutuhkan pencairan (unfreezing) status quo, yakni dominasi kekuasaan itu harus dicairkan dengan menerapkan aturan; perpindahan (moving) ke keadaan yang baru, yakni adanya estapet kekuasaan sesuai yang telah direncanakan; dan pembekuan kembali (refreezing) perubahan tersebut agar menjadi permanen, yakni penetapan dengan keputusan (Asmawi, 2005: 68).

Berkaitan dengan mutu pendidikan, yang perlu mendapat perhatian bukan hanya dosen yang berkualitas dan berbobot, standar isi, proses, sarana dan prasarana, pengelolaan, pembiayaan, dan penilaian pendidikan, tetapi kompetensi lulusan juga perlu dibangun sedemikian rupa mengingat ini memiliki keterkaitan dalam rangka organisasi menjadi lebih efektif dan efisian.

Berkenaan dengan penyerapan lulusan perguruan tinggi, sampai sekarang masih menjadi perdebatan yang belum selesai dikarenakan adanya perbedaan di dalam melakukan pendekatan. Sedikitnya ada dua pendekatan yang berbeda; yakni pendekatan dari dunia kerja dan pendekatan kalangan perguruan tinggi. Pedekatan pertama, menyatakan bahwa lulusan perguruan tinggi tidak mampu bekerja sebagaimana yang diinginkan dunia kerja, yakni keahlian yang dimiliki masih jauh dari harapan. Pendekatan pertama 


\section{r.ecros}

menuntut lulusan perguruan tinggi harus memiliki keterampilan kerja (skill) yang memadai dan siap untuk bekerja. Kalangan perguruan tinggi sebenarnya menanggapi dan merespon tuntutan tersebut, sehingga disiapkan berbagai sarana dan prasarana, seperti komputerisasi; laboratorium, bengkel kerja dan pusat data. Namun pada kenyataannya dalam membentuk keahlian tersebut kurang memadai dan tidak menyebar secara merata di setiap perguruan tinggi.

Pendekatan kedua, dari kalangan perguruan tinggi menyatakan bahwa harapan lulusan mereka adalah sesuai dengan tujuan pendidikan yakni untuk berkembangnya potensi peserta didik agar menjadi manusia yang beriman dan bertakwa kepada Tuhan yang Maha Esa, berakhlak mulia, sehat, berilmu, cakap, kreatif, mandiri, dan menjadi warga negara yang demokratis serta bertanggung jawab (Pasal 4 UU RI Nomor 20 Tahun 2003). Pada pendekatan kedua ini tujuan pendidikan tidak disiapkan hanya untuk siap kerja, tetapi lebih luas lagi untuk membentuk peserta didik menjadi manusia seutuhnya melalui keterampilan yang merupakan hal penting yang dapat dimiliki oleh seseorang. Namun demikian, seyogyanya perbedaan dua pendekatan yang berbeda ini harus dikembangkan dan dipahami sehingga dapat ditarik benang merahnya.

Pedidikan sebagai suatu proses, pertama mengenal adanya raw-input dan instrumental input. Raw input merupakan peserta didik (mahasiswa) sedangkan instrumental input terdiri dari: gedung, perpustakaan, pedoman akademik, dosen, kurikulum, metode dan lain-lain. Kedua raw input dan instrumental input masuk dalam proses yang akan memakan waktu delapan (8) semester. Sedangkan output (lulusan perguruan tinggi) diharapkan sesuai dengan kriteria institusi dan siap untuk masuk kedalam persaingan sumber daya manusia.

\section{Peningkatan Mutu Mahasiswa}

Untuk dapat menghasilkan produk yang baik, maka harus menanam bibit-bibit yang baik. Untuk mendapatkan bibit yang baik perlu seleksi yang baik pula. Kendalanya yang dihadapi di hampir perguruan tinggi termasuk Perguruan Tinggi Agama Islam dalam 


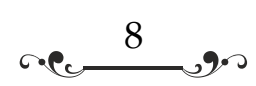

mendapatkan calon mahasiswa baru yang mempunyai kualitas baik adalah terbentur dengan beberapa faktor misalnya dengan motto perguruan tinggi: Biaya Terjangkau Mutu Terjamin, yang harus tetap dilaksanakan. Sistem seleksi banyak yang belum mempertimbangkan segi mutu calon mahasiswa yang sesungguhnya, karena standar kelulusan untuk bisa diterima di suatu fakultas belum begitu ketat dilakukan.

Penerapan seleksi yang mengedepankan mutu dan target penerimaan mahasiswa baru sebanyak-banyaknya masih menjadi pertimbangan yang belum bisa dilaksanakan. Satu sisi penting untuk menerima calon mahasiswa yang bermutu, tetapi dari sisi yang lain dihadapkan pada target minimal; yang juga sulit untuk menentukan jumlah minimalnya. Dengan mendapatkan jumlah mahasiswa yang memadai, maka perguruan tinggi tersebut akan memiliki dukungan dana yang kuat; karenanya cenderung menerima jumlah mahasiswa sebanyak-banyaknya. Untuk dapat meningkatkan mutu pendidikan, hendaknya perlu adanya penjaringan dengan seleksi yang ketat untuk mahasiswa baru agar calon mahasiswa yang diterima mempunyai standar kualitas yang baik, karena bagaimanapun juga mahasiswa tidak lepas dari tanggung jawab terhadap perkembangan sebuah perguruan tinggi.

Disamping itu tingkat kedisiplinan mahasiswa perlu ditingkatkan, karena melalui disiplin yang tinggi mahasiswa benarbenar dapat mandiri dan bertanggung jawab terhadap dirinya sendiri dan ilmu pengetahuan yang diterimanya. Untuk menambah mutu serta kemampuan mahasiswa semasih dia mengikuti perkuliahan di perguruan tinggi, maka perlu ditambah dengan kemampuan berorganisasi, sebab di dalam organisasi mereka akan mampu mengembangkan potensi pribadi dan menambah pengalaman guna menunjang ilmu pengetahuan yang diterimanya.

\section{Makna Pengembangan Soft Skill}

Terdapat beragam definisi tentang soft skills salah satunya yang dikemukakan oleh LaFrance (2016: 4) bahwa soft skills didefinisikan sebagai "personal and interpersonal behaviour that develop and maximize human performance (e.g. confidence, flexibility, honesty, and integrity)" yang berarti bahwa soft skills merupakan 


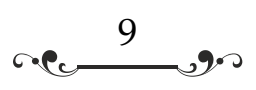

"perilaku personal dan interpersonal yang mengembangkan dan memaksimalkan kinerja seseorang terkait kepercayaan diri, fleksibilitas, kejujuran dan integritas diri". Senada dengan definisi LaFrance, Elfindri dkk (2011: 67) juga mendefinisikan soft skills sebagai "keterampilan dan kecakapan hidup, baik untuk diri sendiri, berkelompok, atau bermasyarakat, serta dengan Sang Pencipta".

Peggy (2007, dalam Illah 2007: 17), mengatakan bahwa "soft skills encompass personal, social, communication, and self management behaviours, they cover a wide spectrum: self awareness, trustworthiness, conscientiousness, adaptability, critical thinking, organizational awareness, attitude, innitiative, emphathy, confidence, integrity, self-control, leadership, problem solving, risk taking and time management".

Sedangkan Illah Sailah (2008: 19) berpendapat bahwa soft skills adalah "keterampilan seseorang dalam berhubungan dengan orang lain (inter-personal skills) dan keterampilan dalam mengatur dirinya sendiri (intra-personal skills) yang mampu mengembangkan secara maksimal unjuk kerja (performans) seseorang". Atribut soft skills, dengan demikian meliputi nilai yang dianut, motivasi, perilaku, kebiasaan, karakter dan sikap.

Berdasarkan definisi di atas diperoleh tiga catatan penting. Pertama, bahwa pada dasarnya soft skills merupakan kemampuan yang sudah melekat pada diri seseorang, tetapi dapat dikembangkan dengan maksimal dan dibutuhkan dalam dunia pekerjaan sebagai pelengkap dari kemampuan hard skills. Kedua, soft skills dibedakan menjadi dua macam, yaitu: soft skills yang terkait dengan personal, contohnya kemampuan mengendalikan emosi dalam diri, dapat menerima nasehat orang lain, mampu memanajemen waktu, dan selalu berpikir positif; dan soft skills yang terakait dengan intra personal, contohnya kemampuan berhubungan atau berinteraksi dengan orang lain, bekerja sama dengan kelompok lain, dan lain lain. Ketiga, bahwa soft skills merupakan komplemen dari hard skills. Jika hard skills berkaitan dengan IQ, otak kiri serta kemampuan teknis dan akademis seseorang yang diperlukan dalam dunia kerja; maka soft skills berkaitan dengan EQ, otak kanan serta kemampuan nonteknis dan non-akademis seseorang yang diperlukan dalam kehidupan sehari-hari. 


$$
\text { rect } 10 \text {, g. }
$$

Selanjutnya, soft skills itu memiliki jenis dan bentuk yang berbeda-beda sebagaimana yang dipaparkan oleh Aly (2017: 43-44) dalam tabel berikut:

\begin{tabular}{|l|l|}
\hline Jenis Soft skill & Bentuknya \\
\hline Personal & Manajemen waktu \\
& Manajemen stress \\
& Manajemen perubahan \\
& Karakter transformasi \\
& Berpikir kreatif \\
& Memiliki acuan tujuan positif \\
\hline Intra-Personal & Kemampuan memotivasi \\
& Kemampuan memimpin \\
& Kemampuan negosiasi \\
& Kemampuan presentasi \\
& Kemampuan komunikasi \\
& Kemampuan membuat relasi \\
& Kemampuan bicara di muka \\
umum mabungan antara Personal dan & Kejujuran, \\
\hline Tanggung jawab, \\
Berlaku adil, \\
Kemampuan bekerja sama, \\
Kemampuan beradaptasi, \\
Kemampuan berkomunikasi, \\
Toleran, \\
Hormat terhadap sesama, \\
Kemampuan \\
keputusan, \\
dan Kemampuan memahkan \\
masalah \\
\hline
\end{tabular}

Jika soft skills yang bersifat personal memiliki 6 (enam) bentuk, maka soft skills yang bersifat intra personal memiliki 7 (tujuh) bentuk. Sementara itu, kedua bentuk soft skills tersebut selanjutnya digabungkan menjadi 10 (sepuluh) bentuk yaitu: (1) kejujuran, (2) tanggung jawab, (3) berlaku adil, (4) kemampuan 


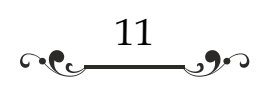

bekerja sama, (5) kemampuan beradaptasi, (6) kemampuan berkomunikasi, (7) toleran, (8) hormat terhadap sesama, (9) kemampuan mengambil keputusan, dan (10) kemampuan memecahkan masalah (Illah: 2008: 1920). Kesepuluh jenis soft skills tersebut merupakan gabungan dari keterampilan mahasiswa dalam mengatur dirinya sendiri dan keterampilan dalam berhubungan dengan orang lain. Lebih lanjut dinyatakan bahwa kesepuluh jenis soft skills inilah yang berkontribusi sekitar 80\% terhadap keberhasilan mahasiswa dalam berbagai jenis profesi dan pekerjaan.

\section{Pengembangan Soft Skill dalam Proses Pembelajaran}

Proses pembelajaran di perguruan tinggi sedang mengalami pergeseran dari pembelajaran berbasis isi ke berbasis kompetensi. Apabila kurikulum ini dijalankan, maka tidak terlalu sulit untuk mahasiswa merubah dirinya dari yang kurang kompeten menjadi lulusan yang kompeten. Perubahan yang dimaksud dalam SK Mendiknas 045/U/2002, bukan semata-mata hanya mengganti daftar mata kuliah atau susunan mata kuliah, melainkan yang lebih hakiki adalah perubahan proses pembelajaran, penyampaian dan evaluasinya. Proses pembelajaran dari teacher centered ke student centered learning.

Pendidikan yang berfokus hanya pada isi sudah seharusnya bergeser pada proses. Saat ini kepemilikan pembelajaran bukan lagi berpusat pada dosen melainkan mahasiswa yang mana mereka aktif mengkonstruksikan ilmu pengetahuan, sehingga penekanan bukan lagi hanya pada teori melainkan juga pada bagaimana suatu pekerjaan dikerjakan. Oleh karenanya, perubahan pada kurikulum menjadi penting adanya, dari kurikulum berbasis isi menjadi kurikulum berbasis kompetensi. Proses pembelajaran yang menggunakan pendekatan student centered learning memberikan ruang lingkup yang luas untuk pengembangan soft skills. Soft skills dikembangkan tidak seharusnya melalui satu mata kuliah, melainkan di selipkan di setiap mata kuliah. Apabila atribut soft skills yang akan dikembangkan adalah komunikasi lisan, maka proses pembelajaran yang menggunakan presentasi, diskusi, diskusi kelompok menjadi perlu dilakukan. Namun, apabila kerjasama yang akan difokuskan, maka penugasan berkelompok perlu dilakukan. 


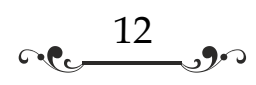

Pengembangan soft skills di perguruan tinggi dapat dilakukan melalui kegiatan proses pembelajaran dan juga kegiatan kemahasiswaan dalam kegiatan ekstra kurikuler atau ko- kurikuler. Yang terpenting, soft skills ini bukan bahan hafalan melainkan dipraktekkan oleh individu yang belajar atau yang ingin mengembangkannya. Pengembangan soft skills dalam proses pembelajaran dapat dilakukan melalui kegiatan belajar melalui tatap muka di dalam kelas maupun praktek di laboratorium atau lapangan. Pengembangan soft skills melalui kurikulum dapat ditempuh dengan dua cara. Pertama, melalui kegiatan pembelajaran yang secara ekplisit diintegrasikan dalam mata kuliah yang dituangkan dalam Silabus, SAP (Satuan Acara Perkuliahan) atau RPP (Rencana Pelaksanaan Pembelajaran). Kedua, dapat dilakukan melalui proses hidden curriculum, yaitu suatu strategi pengembangan soft skills yang disampaikan oleh dosen kepada mahasiswa secara terintegrasi pada saat perkuliahan berlangsung. "Hidden curriculum is the broader concept of which the informal curriculum is a part" yang berarti pelajaran dari kurikulum tersembunyi diajarkan secara implisit. Kurikulum tersembunyi lebih ampuh karena dapat membuat proses pembelajaran lebih menarik minat dan menyenangkan. Peran dosen dalam hal ini adalah: membangun proses dialog, menangani dinamika kelompok, terlibat dengan motivasi mahasiswa, mengintroduksikan berpikir kritis, dan memberdayakan kurikulum tersembunyi (Empowering Hidden Curriculum).

Dengan demikian, maka kesuksesan mahasiswa dalam mengikuti perkuliahan juga ditentukan oleh faktor soft skills selain hard skills (potensi akademiknya). Untuk meningkatkan soft skills mahasiswa salah satunya dapat ditempuh dengan cara mensinergikan antara soft skills dan hard skills dalam perkuliahan.

Fallon (2015: 3) seorang trainer soft skills di New York berpendapat: "Bahwa soft skills mahasiswa itu bukan hanya dapat dikembangkan melainkan juga dapat diajarkan oleh para dosen di perguruan tinggi". Senada dengan pendapat ini, Felix Day menyatakan "bahwa mahasiswa itu memerlukan soft skills untuk keberhasilannya pada karir dan dunia kerja, oleh karena itu materi soft skills perlu diajarkan kepada para mahasiswa di perguruan tinggi" (Day, 2012: 5). 


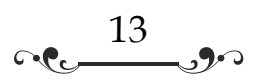

Christoph Hansert, seorang pakar dalam bidang pengembangan pendidikan dari Jerman (dalam Illah, 2008: 46), menyarankan: "Agar pengembangan soft skills untuk mahasiswa Indonesia dilakukan dengan cara menjalin jejaring kerja (networking) dosen Indonesia dengan dosen luar negeri yang melibatkan mahasiswa, misalnya dalam bidang penelitian. Dengan jejaring ini, mau tidak mau mahasiswa akan terpaksa berkomunikasi tulisan dengan menggunakan bahasa asing. Suatu saat mahasiswa ini difasilitasi untuk bertemu bertukar pikiran, saling menghargai pendapat, mempelajari budaya orang lain dan belajar bekerjasama dalam tim".

\section{Peningkatan Mutu Calon Guru PAI melalui Pengembangan Soft Skill}

Sekolah Tinggi Agama Islam Kudus sebagai salah satu Perguruan Tinggi Keagamaan Islam Negeri di Indonesia telah melakukan beberapa penguatan dalam meningkatkan mutu lulusannya terutama calon guru PAI sebagai salah satu lulusan terbanyak di perguruan tinggi tersebut. Diantaranya penguatan dalam tingkat intra-kurikuler maupun ko-kurikuler.

Penguatan dalam tingkat intra-kurikuler dilakukan melalui dua komponen, yakni komponen ke-Islam-an dan komponen PAI. Dalam komponen ke-Islam-an, mahasiswa dibekali muatan intrakurikuler Praktik Ibadah. Sedangkan dalam komponen PAI, mahasiswa dibekali muatan intra-kurikuler Fiqh, Ushul Fiqh, Ilmu Kalam, Akhlaq, Ulumul Qur'an, Ulumul Hadits, Hadits, Tafsir,Materi PAI, Tasawuf.

Penguatan di tingkat bidang studi tidak cukup kalau tidak diseimbangkan dengan kompetensi pembelajaran pada mahasiswa. STAIN Kudus melakukan langkah yang berbeda dalam membekali penguasaan kompetensi pembelajaran untuk mahasiswa PAI yakni melalui: metodologi PAI, Strategi Pembelajaran Fiqh, Strategi Pembelajaran Qur'an Hadis, Strategi Pembelajaran SKI, Strategi Pembelajaran Aqidah Akhlak, Perencanaan Sistem PAI, Pengembangan Evaluasi, Pengembangan Kurikulum PAI, Analisis Kurikulum PAI, Micro Teaching, PPL, Pengembangan Bahan Ajar dan 


\section{r.e. 14}

Media, Program Aplikasi, Praktikum Aplikasi Komputer untuk Bahan Ajar.

Mahasiswa PAI di STAIN Kudus dilatih untuk mengembangkan kompetensi profesionalnya melalui program PPL dan KKN. Kegiatan ini sebenarnya mengajarkan pada mahasiswa memiliki kesempatan untuk Learning to Be dan Learning to Live Together. Itu berarti mahasiswa mendapatkan bekal soft-skill. Hal tersebut dikarenakan soft skill menurut Berthal yang dikutip (Harmoni, th): Soft skill is "personal and interpersonal behaviors that develop and maximize human performance (e.g. coaching, team building, decision making, initiative). Soft skills do not include technical skills, such as financial, computer or assembly skills". Pendapat tersebut menunjukkan bahwa keikutsertaan mahasiswa dalam kegiatan PPL dan KKN dapat memaksimalkan personal and interpersonal behaviors that develop and maximize human performance.

Pendapat lain dinyatakan Bennett et al. (Choiriyah, dkk., 2013: 376) 'soft skills' as those skills which can support study in any discipline and also skills that have the potential to be transferred to a range of contexts, education and workplace. Pengertian tersebut menunjukkan bahwa skill dapat mendukung seseorang untuk berkembang di lembaga pendidikan dan tempat kerja. Dari sini terlihat kepemilikian seseorang atas soft skill menjadikan seseorang bisa semakin fleksibel dimanapun seseorang berada.

Hard skill meliputi kemampuan kognitif dan psikomotorik yang berkaitan dengan belajar untuk melakukan dan belajar untuk tahu. Sedangkan soft skill meliputi kemampuan afektif berkaitan dengan belajar untuk menjadi diri sendiri dan belajar untuk hidup bersama. Calon guru PAI yang tidak mengikuti kegiatan PPL dan KKN hanya akan mendapatkan bekal learning to know dan learning to do. Akan tetapi ketika mereka mengikuti kegiatan secara penuh akan memperkuat bekal learning to be dan learning to live together. Penguasaan pembelajaran ini menjadikan mahasiswa menguasai soft skill yang sangat diperlukan di dunia kerja. Dunia kerja di lembaga pendidikan juga harus memiliki soft skill sekaligus hard skill. Dengan keikutsertaan mahasiswa dalam kegiatan PPL dan KKN menjadikan lebih siap untuk menghadapi siswa, teman sejawat ketika bekerja 


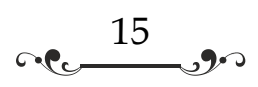

dan stakeholder lain. Hal ini memberikan nilai lebih dibandingkan ketika mahasiswa hanya mengikuti kegiatan intra-kurikuler di perkuliahan semata.

Partisipasi mahasiswa dalam kegiatan lapangan tersebut sekaligus akan memiliki empat hal yang diperlukan dalam pekerjaan nantinya. Empat hal tersebut menurut Prayudi (2008, dalam Choiriyah, dkk., 2013: 377-378) adalah:

a. pengetahuan atau keterampilan khusus atau kompetensi teknis (hard skill), termasuk di dalamnya juga pengetahuan mengenai industri atau organisasi;

b. pengalaman di suatu bidang atau sering dikenal sebagai jam terbang;

c. kompetensi perilaku atau sering juga disebut soft skill/managerial skill dan

d. kepribadian.

Keempatnya bisa dibentuk ketika masa perkuliahan yang dikategorikan Patrick S. O’Brien (1996, dalam Choiriyah, dkk., 2013: 378), tujuh area soft skill yang disebut sebagai Winning Characteristics, yaitu: communication skills, organizational skills, leadership, logic, effort, group skills, dan ethics. Tujuh karaktersitik ini disamping bisa dibentuk di tingkat kegiatan kokurikuler dan ekstra kurikuler tetapi juga bisa dibentuk di kegiatan intra kurikuler. Semestinya, setiap dosen memiliki model dan metode yang sama dalam menyisipkan proses pembentukan soft skill melalui aktivitas perkuliahan mereka.

Pernyataan tersebut dikuatkan Tony Wagner (2008, dalam Choiriyah, dkk., 2013: 378) bahwa ketika lembaga dunia kerja mengalami perubahan diperlukan seseorang yang memiliki kecakapan bertahan hidup sebanyak tujuh hal bagi tenaga kerjanya yaitu:

a. Critical thinking and problem solving. Problem solving memiliki tiga area, yaitu: making decisions under constraints, evaluating and designing systems for a particular situation, trouble-shooting a malfunctioning device or system based on a set of symptoms.

b. Collaboration across networks and leading by influence.

c. Agility and adaptability.

d. Initiative and entrepreneuralism. 


$$
\text { recus }
$$

e. Effective oral and written communication.

f. Accessing and Analyzing Information.

g. Curiosity and imagination.

Seorang tenaga kerja terutama seorang guru harus memiliki kecakapan berpikir kritis dan pemecahan masalah (membuat keputusan dibawah tekanan, mengevaluasi dan merancang system untuk situasi tertentu, dan mampu menemukan masalah dari ketidakberfungsian alat atau system dari gejala-gejala yang muncul), mampu membuat jaringan, menyesuaikan diri, inisiatif dan berwirausaha, mampu berkomunikasi lisan dan tulisan secara efektif, mampu mengakses dan menganalisa informasi, serta penuh imajinasi. Seorang calon guru harus dipersipakan memiliki kemampuan tersebut sehingga memberikan dampak perubahan di lembaga pendidikan.

Perubahan dunia kerja di lembaga pendidikan harus disiapkan oleh Perguruan Tinggi yang mempersiapkan tenaga pendidik dan tenaga kependidikan lainnya sehingga seorang mahasiswa harus dididik dan dilatih untuk memiliki kompetensi yang terjabarkan dalam tiga tingkatan; melakukan, mengelola, dan mengevaluasi serta memodifikasi proses. Dengan demikian seseorang yang memiliki soft skill yang tinggi adalah orang yang memiliki tiga tingkat sekaligus. Masing-masing tingkatan tersebut memiliki dua element yaitu elemen must have dan good to have seperti yang tergambar berikut (Sharma, 2009, dalam Choiriyah, dkk., 2013: 379-380):

\begin{tabular}{|l|l|l|l|}
\hline No. & Soft skills & \multicolumn{1}{|c|}{$\begin{array}{c}\text { Must Have } \\
\text { Elements } \\
\text { (Sub-skills) }\end{array}$} & \multicolumn{1}{|c|}{$\begin{array}{c}\text { Good to Have } \\
\text { Elements } \\
\text { (Sub-skills) }\end{array}$} \\
\hline 1 & $\begin{array}{l}\text { Communicati } \\
\text { ve skills }\end{array}$ & $\begin{array}{l}\text { Ability to deliver } \\
\text { idea clearly, } \\
\text { effectively and } \\
\text { with confidence } \\
\text { either orally or in } \\
\text { writing }\end{array}$ & $\begin{array}{l}\text { Ability to use } \\
\text { technology during } \\
\text { presentation. } \\
\text { Ability to discuss } \\
\text { And arrive at a }\end{array}$ \\
& & $\begin{array}{l}\text { ansensus. } \\
\text { constice } \\
\text { Ability to }\end{array}$ \\
\hline
\end{tabular}




\begin{tabular}{|c|c|c|c|}
\hline & & $\begin{array}{l}\text { active listening } \\
\text { skill and respond. } \\
\text { Ability to present } \\
\text { clearly and } \\
\text { confidently to the } \\
\text { audience. }\end{array}$ & $\begin{array}{l}\text { communicate with } \\
\text { individual from a } \\
\text { different cultural } \\
\text { background. } \\
\text { Ability to expand } \\
\text { one's own } \\
\text { communicative } \\
\text { skill. } \\
\text { Ability to use non- } \\
\text { oral skills. }\end{array}$ \\
\hline 2 & $\begin{array}{l}\text { Critical } \\
\text { thinking and } \\
\text { problem } \\
\text { solving skills }\end{array}$ & $\begin{array}{l}\text { Ability to identify } \\
\text { and analyze } \\
\text { problems in } \\
\text { difficult situation } \\
\text { and make } \\
\text { justifiable } \\
\text { evaluation. } \\
\text { Ability to expand } \\
\text { and improve } \\
\text { thinking skills such } \\
\text { as explanation, } \\
\text { analysis and } \\
\text { evaluate } \\
\text { discussion. } \\
\text { Ability to find ideas } \\
\text { and look } \\
\text { for alternative } \\
\text { solutions. }\end{array}$ & $\begin{array}{l}\text { Ability to think } \\
\text { beyond. } \\
\text { Ability to make } \\
\text { conclusion based } \\
\text { on valid proof. } \\
\text { Ability to withstand } \\
\text { and give full } \\
\text { responsibility. } \\
\text { Ability to } \\
\text { understand and } \\
\text { accommodate } \\
\text { oneself to the } \\
\text { varied working } \\
\text { environment. }\end{array}$ \\
\hline 3 & Teamwork & $\begin{array}{l}\text { Ability to build a } \\
\text { good rapport, } \\
\text { interact and work } \\
\text { effectively with } \\
\text { others. } \\
\text { Ability to } \\
\text { understand and } \\
\text { play the role of a }\end{array}$ & $\begin{array}{l}\text { Ability to give } \\
\text { contribution to the } \\
\text { planning and } \\
\text { coordinate group } \\
\text { work. } \\
\text { Responsible } \\
\text { towards group } \\
\text { decision. }\end{array}$ \\
\hline
\end{tabular}


recus

\begin{tabular}{|c|c|c|c|}
\hline & & $\begin{array}{l}\text { leader and } \\
\text { follower } \\
\text { alternatively. } \\
\text { Ability to } \\
\text { recognize and } \\
\text { respect other's } \\
\text { attitude, behavior } \\
\text { and beliefs. }\end{array}$ & \\
\hline 4 & $\begin{array}{l}\text { Life-long } \\
\text { learning and } \\
\text { information } \\
\text { management } \\
\text { skills }\end{array}$ & $\begin{array}{l}\text { Ability to find and } \\
\text { manage relevant } \\
\text { information from } \\
\text { various sources. } \\
\text { Ability to receive } \\
\text { new ideas } \\
\text { performs } \\
\text { autonomy } \\
\text { learning. }\end{array}$ & $\begin{array}{l}\text { Ability to develop } \\
\text { an inquiry mind } \\
\text { and seek } \\
\text { knowledge. }\end{array}$ \\
\hline 5 & $\begin{array}{l}\text { Entrepreneur } \\
\text { ship skills }\end{array}$ & $\begin{array}{l}\text { Ability to identify } \\
\text { job opportunities. }\end{array}$ & $\begin{array}{l}\text { Ability to propose } \\
\text { business } \\
\text { opportunity. } \\
\text { Ability to build, } \\
\text { explore and seek } \\
\text { business } \\
\text { opportunities and } \\
\text { job. } \\
\text { Ability to be self- } \\
\text { employed. }\end{array}$ \\
\hline 6 & $\begin{array}{l}\text { Ethics, moral } \\
\text { and } \\
\text { profesional }\end{array}$ & $\begin{array}{l}\text { Ability to } \\
\text { understand the } \\
\text { economy crisis, } \\
\text { environment and } \\
\text { social cultural } \\
\text { aspects } \\
\text { professionally. } \\
\text { Ability to analyze } \\
\text { make problem }\end{array}$ & $\begin{array}{l}\text { Ability to practice } \\
\text { ethical attitudes } \\
\text { besides having the } \\
\text { responsibility } \\
\text { towards society. }\end{array}$ \\
\hline
\end{tabular}




\begin{tabular}{|l|l|l|l|}
\hline \multicolumn{3}{|c|}{$\begin{array}{l}\text { solving decisions } \\
\text { related to ethics. }\end{array}$} \\
\hline 7 & $\begin{array}{l}\text { Leadership } \\
\text { skills }\end{array}$ & $\begin{array}{l}\text { Knowledge of the } \\
\text { basic theories of } \\
\text { leadership. } \\
\text { Ability to lead a } \\
\text { project. }\end{array}$ & $\begin{array}{l}\text { Ability to } \\
\text { understand and } \\
\text { take turns as a } \\
\text { leader and follower } \\
\text { alternatively. } \\
\text { Ability to supervise } \\
\text { members of a } \\
\text { group. }\end{array}$ \\
\hline
\end{tabular}

Titik tekan dari pendapat tersebut bahwa soft skill tertinggi adalah leadership skill dan ethics, moral and profesional. Disamping penguatan di atas, mahasiswa dalam menghadapi globalisasi mendapatkan penguatan bahasa asing. Bahasa Asing yang diberikan mahasiswa ada 2, yaitu Bahasa Arab dan Bahasa Inggris.

Pengembangan hard skill dan soft skill dalam kegiatan intra dan ko-kurikuler ini mengarahkan seorang calon guru PAI seperti pendapat Lortie yang dikutip Hamond (2006: 35) untuk tidak hanya berfikir seperti guru (think like a teacher) tetapi juga bertindak seperti guru (act like a teacher). Selama proses pendidikan di lembaga perguruan tinggi semestinya mahasiswa harus secara bersama dibentuk sebagai "think like a teacher" dan "act like a teacher" sehingga mendidik calon guru bersifat on-going process. Proses yang terus menerut sejak pertama mahasiswa masuk di semester 1 dan berkelanjutan sampai menjadi guru. Dengan penguasaan semacam itu memudahkan mahasiswa memiliki kemampuan subject matter knowledge dan pedagogical content knwoledge (Hammond, 2005: 205). Subject matter knowledge dibentuk dan diperkuat di kegiatan intra-kurikuler, sedangkan pedagogical content knwoledge lebih banyak dibentuk melalui kegiatan ko-kurikuler dan ekstra-kurikuler.

\section{Simpulan}

Hasil penelitian menunjukkan bahwa strategi Peningkatan mutu calon Guru Pendidikan Agama Islam di STAIN dibagi menjadi 


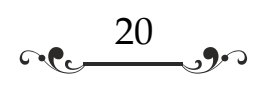

beberapa penguatan, yakni penguatan ke-Islam-an, penguatan bidang studi PAI, maupun penguatan bahasa asing (Bahasa Inggris dan Bahasa Arab), baik yang diberikan melalui kegiatan intrakurikuler maupun ko-kurikuler. Perubahan dunia kerja di lembaga pendidikan harus disiapkan oleh Perguruan Tinggi yang mempersiapkan tenaga pendidik dan tenaga kependidikan lainnya sehingga seorang mahasiswa harus dididik dan dilatih untuk memiliki kompetensi yang terjabarkan dalam tiga tingkatan; melakukan, mengelola, dan mengevaluasi serta memodifikasi proses. Dengan demikian seseorang yang memiliki soft skill yang tinggi adalah orang yang memiliki tiga tingkat sekaligus. Masing-masing tingkatan tersebut memiliki dua element yaitu elemen must have dan good to have.

Selain itu, masih diperlukan adanya sinergi antara Perguruan Tinggi Agama Islam penyelenggaran prodi PAI sehingga ada kesamaan dalam menjamin mutu calon guru PAI. Dengan demikian, Perguruan Tinggi Agama Islam dapat mencetak lulusan yang berkompetensi dan berkualitas, serta berdaya saing tinggi yang mampu menjawab tuntutan sekolah atau madrasah. 


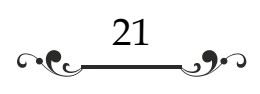

\section{Daftar Pustaka}

Aly, Abdullah. 2017. Pengembangan Pembelajaran Karakter Berbasis Soft skills di Perguruan Tinggi. Ishraqi. Vol. 1 No. 1. Januari 2017 (4051).

Asmawi, M. Rosul. 2005. Strategi Meningkatkan Lulusan Bermutu di Perguruan Tinggi. Makara, Sosial Humaniora. Vol. 9, No. 2. Desember 2005: 66-71.

Choiriyah, Siti, Alwiyah, Noor dan Munadi, Muhammad. 2013. Strategi Peningkatan Mutu Calon Guru Pendidikan Agama di Perguruan Tinggi Agama Islam se Eks Karesidenan Surakarta. 2nd International Seminar on Quality and Affordable Education (ISQAE 2013). 372-382.

Day, Flex. 2012. Our Students Need Soft Skills. Mali: Delta College Press.

Elfindri, dkk., 2010. Soft skills untuk Pendidik. T.k.: Baduose Media.

Fallon, Nicole. 2015. Soft Skills Matter: Can They Be Taught? New York: Business News Daily Assistant Editor.

Hamond, Linda Darling, et. al. 2005. Preparing Teachers for A Changing World What Teachers Should Learn And Be Able to Do. San Francisco: Jossey-Bass.

Hamond, Linda Darling. 2006. Powerful Tacher Education Lessons From Exemplary Programs. San Francisco: Jossey-Bass.

Harmoni, Ati. Tanpa Tahun. Soft skill. Kegiatan Ektrakurikuler, dan Pilihan Karir. ati@staff.gunadarma.ac.id

Indraijaya, Adam I. 1989. Perubahan dan Pengembangan Organisasi. Bandung : Sinar Baru.

LaFrance, Aricia E. Helping Students Cultivate Soft skills. Diakses pada 15 Desember 2016, dari http://www.ncda.org /aws/NCDA/pt/sd/news_article/7010/_PARENT/layout_details_cc /false.

Robbins, Stephen P. Terj. Yusuf Udaya. 1994. Teori Organisasi, Struktur, Desain dan Aplikasi. Jakarta: Arcan.

Sailah, Illah dkk. 2008. Pengembangan Soft skills dalam Proses Pembelajaran di Perguruan Tinggi. Jakarta: Direktorat Akademik, Direktorak Jenderal Pendidikan Tinggi, Departemen Pendidikan Nasional. 


$$
\text { reces } 22
$$

Setditjen Pendidikan Islam. 2008. Data Statistik Pendidikan Tahun 2007/2008. Jakarta: Setditjen Pendidikan Islam Depag.

Sharma, Archna. 2009. Importance of Soft skills development in education.

http://schoolofeducators.com/2009/02/importance-of-soft-skillsdevelopment-in-education/.

Undang-Undang Republik Indonesia Nomor 20 Tahun 2003 Tentang Sistem Pendidikan Nasional. 